\title{
The Need for Collaboration between Agriculture and Healthcare through the Environment
}

\section{Katsu Minami*}

Department of Agriculture, Japan

*Corresponding Author: Katsu Minami, Department of Agriculture, Japan.

Received: June 24, 2019; Published: July 03, 2019

DOI: 10.31080/ASAG.2019.03.0557

Modern agriculture has become an intensive system that, with the use of chemical fertilizers, agricultural chemicals, and synthetic materials, has been able to produce large quantities of food for the growing population.

However, the enormous resources and energy poured into this system of mass production have caused environmental headaches of various kinds, from localized problems such as heavy metal contamination, to more widespread problems such as the eutrophication of rivers, lakes, and marshes due to runoff of nitrogen and phosphorus, and global warming and destruction of ozone layers caused by methane and nitrous oxide emission from agricultural activities. More recently, problem such as dioxin emissions with impacts that span generations have emerged, bringing gave implications for human health and the global environment.

Along with progress in fields of medicine such as microbiology, immunology, clinical medicine and pharmacology, advances in nutrient science have enabled many people to surmount illness and improve their health. At the same time, the many different chemical substances invented or discovered in the processes have given rise to drug-related diseases and other problems, providing insights that have driven the further evolution of clinical medicine. There are also unresolved issues related to "human healing" and so forth.

The goals of preventive medicine in the 21st century include the assessment, management, and communication of risk, prevention of disease, and the improvement of health. To address the expectations of society todays, it is vital now to investigate and establish common ground between these medical issues and agriculture.

The outcomes of $20^{\text {th }}$ century scientific and technological advances suggest very strongly that research and education in agromedicine will be absolutely vital to human society in the $21^{\text {th }}$ century. The need for such research and education to prevent disease, promote health, ensure food safety, practice environment-friendly agriculture, benefit from the therapeutic value of agriculture, and otherwise ensure human happiness cannot be overstated. Considering the veracity of the saying "We are what we eat", I feel that not enough attention has been paid to agromedical research and education.

A major problem in modern society is disjunction in its various forms: disjunction between people, between teachers and students, between soil and nature and people, between facts, between culture and history and present time, and so forth. The list could go on and on, but disjunction illness could be divided roughly into four categories: disjunction between from knowledge and knowledge, between knowledge and action, between knowledge and feelings, and between past and present knowledge.

Disjunction exists also between agriculture and medicine, and surmounting this disjunction requires an all-embracing, multi-disciplinary approach to research and education in areas of overlap between agriculture and medicine.

Kitasato University has long dedicated itself to the comprehensive pursuit of life sciences, but agromedicines is nevertheless a relatively new field for us. Kitasato University has begun to integrate agriculture, environment and medicine as a model for the development of the unified intellectual approach from 2005 [1-3].

I want to look here at a number of different international initiatives and topics in agromedicine. Below are some examples of international initiatives.

The North American Consortium (NAAC) [4].

NAAC has been publishing the "Journal of Agromedicine" and a newsletter since it was established in 1988, and there are a number of other publications which I will skip owing to lack of space.

International Nitrogen Initiative (INI) [5]

More than a century has gone by since the Haber-Bosch process was first used to fix atmospheric nitrogen, and currently more than $270 \mathrm{Tg}\left(10^{12} \mathrm{~g}\right)$ of nitrogen is being fixed every year. Surplus fixed nitrogen is beginning to have major impacts on the natural 
environment and human communities, such as nitrate-polluted groundwater, eutrophication, destruction of the ozone layer, global warming, blue baby syndrome, nitrate-polluted crops and livestock, effects on human health, and so forth. There is an urgent need for research on the effects on human health of surplus nitrogen in food and the environment, and for the implementation of appropriate countermeasures. The International Nitrogen Initiative was launched to address this issue.

\section{European Nutrigenomics Organization (NuGO) [6]}

Nutrigenomics is the study of how nutrients from food affect the expression and regulation of genes. There has never been a greater need than there is now for research in combined fields, and nutrigenomics is one such combined field. Nutrigenomics combines elements of genomics, computer science, immunology, pathology, agriculture, oceanography, environmental science, analytical chemistry, and life sciences in relation to various foodstuffs to assess health, illness, and stages in between from the viewpoint of diet. As such, nutrigenomics is a combined field that feeds into agromedicine.

Persistent organic pollutants (POPs) [7]

POPs are not only highly toxic, but also degrade only very slowly in the environment, and tend to accumulate within living organisms. POPs circulate through the atmosphere, soil, water, and organisms to contaminate manufactured foodstuffs. Currently aldrin and eleven other substances are subject to the Stockholm Convention on POPs.

Codex Alimentarius Commission (Codex) [8]

Created jointly by the FAO and WHO, the Codex is an international food standards organization dedicated to protecting the health of consumers and ensuring fair trade practices in the food trade. For example, the Commission's Ad Hoc Intergovernmental Task Force on Food Derived from Biotechnology handles such issues as latent risks to human health of consuming food products derived from genetically modified (GM) animals, food products derived from GM plants that can contribute to nutrition or health, GM adulteration, and GM plant-derived foods containing pharmacological ingredients and bioactive substances.

Global Environmental Change and Human Health (GECHH) [9]

One of the components of the International Geosphere-Biosphere Programme (IGBP) is the Earth System Science Partnership (ESSP). ESSP activities include joint projects, one of which, Global Environmental Change and Human Health (GECAHH), emphasizes the need for linkage between agriculture, environment, and medicine.
Considering the above agromedicine research and education activities will, in my mind, require the establishment of Agromedicine Research and Education Center staffed by a collection of specialists in food science, nutrition, agriculture, immunology and other disciplines.

\section{Bibliography}

1. Kitasato University.

2. Agriculture-Environment-Medicine: Ed. Katsu Minami, Kitasato University Agromedicine Series 7, Yokendo (2009).

3. Kitasato University.

4. NAAC.

5. INI

6. NuGO.

7. POPs.

8. Codex.

9. GECHH.

Volume 3 Issue 8 August 2019

(C) All rights are reserved by Katsu Minami. 